\title{
Aggregate sizes regulate the microbial community patterns in sandy soil profile
}

\author{
Yifei Sun ${ }^{1}$, Meiling Sun ${ }^{1}$, Guowei Chen ${ }^{2}$, Xin Chen ${ }^{1}$, Baoguo $\mathrm{Li}^{1}$, Gang Wang ${ }^{1, *}$ \\ 1 Department of Water \& Soil Sciences, China Agricultural University, Beijing 100049, China \\ 2 Department of Civil Engineering, Hefei University of Technology, Hefei 230000, China
}

\section{H I G H L I G H T S}

- Relative abundances of microbial communities were most related to aggregate proportions in clay-layer soils.

- Aggregate content with $<0.053 \mathrm{~mm}$ in claylayer soil significantly influence the diversity of soil microbial community.

- Complexity of microbial interactions raised along increasing precipitation across sampling sites.

- Competition for substrates induced niche differentiation in deeper soils.

\section{ARTICLE INFO}

Article history:

Received October 26, 2020

Revised April 9, 2021

Accepted April 17, 2021

Keywords:

Aggregate distributions

16S rRNA

Microbial community

Sandy soil

Network analysis

Soil profile
GRAPHICAL ABSTRACT
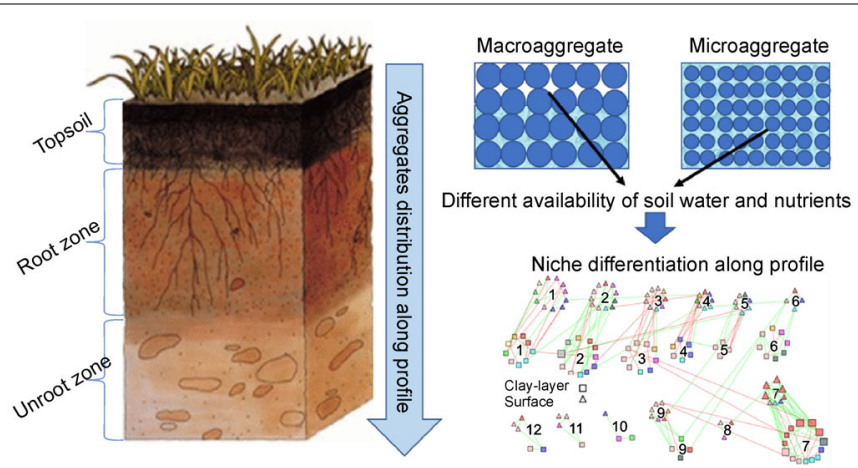

$>$ Small-size aggregates greatly contribute to the variations of microbial communities and ecological niche.

\section{A B S T R A C T}

Soil microorganisms play a key role in the function of soil ecosystem, yet our knowledge about how microbial communities respond to the typically sandy soil environmental properties along the soil profile is still insufficient. We investigated the soil microbial community patterns from top $(0-20 \mathrm{~cm})$ to clay-layer $(>80 \mathrm{~cm})$ of the typical sandy soils in three regions in China with different levels of precipitation, including Lishu County in Jilin Province (LS), Langfang City in Hebei Province (LF) and Zhengzhou City in Henan Province (ZZ). Our findings showed that small-size aggregates $(<0.5 \mathrm{~mm}$ ) rather than large ones $(\geqslant 0.5 \mathrm{~mm})$ dominated the soil profile. The relative abundances of Actinobacteria, Crenarchaeota and Firmicutes were highly related to aggregate proportions of the deep clay-layer soil. The network analysis revealed the distinct community patterns among modules, evidencing niche differentiation along the soil profile. The keystone species OTU_11292 was observed having migrated clearly into the other module of the clay-layer soil. Different roles of the OTU_30 (belonging to Gemmatimonadetes) in soil processes might partly explain the different microbial distribution between top- and clay-layer soils. These findings provided new insights into the candidate mechanisms of microbial diversity maintenance and community patterning of sandy soils, which were necessary for better understanding of ecological rules guiding long-term agricultural practice.

(C) Higher Education Press 2021

\footnotetext{
* Corresponding author

E-mail address: gangwang@cau.edu.cn (G. Wang)
} 


\section{Introduction}

Microbial community composition is a key control of a host of essential processes for soil productivity and sustainability. The majority studies of soil microbiology have focused on the surface soil profiles where microbial numbers and biochemical activities are higher (Marschner et al., 2003; Drenovsky et al., 2004; Barber et al., 2017). Soil profiles are often a few to several meters deep with large numbers of microorganisms residing in subsurface horizons (Blume et al., 2002). Studies have shown that microbial community compositions and biological properties vary with differing pedogenetic layers as well as the microbial biomass and metabolic activities (Ekelund et al., 2001; Castellazzi et al., 2004; Sanesi and Certini, 2005). Deeper layers of soil may contain microbial communities that are specialized for their niches, and could be fundamentally distinct from their shallow neighbors (Fritze et al., 2000; Blume et al., 2002). Knowledge about the candidate mechanisms for driving soil microbial community structure and functions is helpful to fully understand the soil microbial ecology, yet our understanding about the nature of the microbial communities across the deep soil profile is still insufficient.

Key soil environmental properties, such as soil $\mathrm{pH}$, oxygen, temperature, nutrient contents and resource availabilities are considered to shape soil microbial communities in deeper layers (Eilers et al., 2012; Kramer et al., 2013; Xu et al., 2021). The quantity and quality of soil organic matters (SOM) decline through soil profiles because the input of root exudates and surface litters are richer in surface than deeper horizons (Trumbore, 2000) and thereby, strongly influencing microbial community composition. Microbial community composition also shifts along the soil depth, e.g., increasing relative abundance of bacterial populations along the soil depth that are mainly attributed to the difference in available phosphorus, exchangeable calcium and soil water availability (Fierer et al., 2003). The total microbial biomass strongly decreases with soil depth due to the variation in soil carbon $(\mathrm{C})$ and nitrogen $(\mathrm{N})$ contents (Allison et al., 2010). The spatial configurations of soil $\mathrm{C}$ and $\mathrm{N}$ are further intensified by the heterogeneity of soil structural characteristics from pore to aggregates. Soil aggregates are considered as the building block of soil structure, whereby moisture, oxygen (and other gases) and nutrients fluctuate among soil profiles, leading to the vertical variations in the abundance and composition of soil microbial communities (Eilers et al., 2012). Soil aggregates (often with different sizes) supply physical protection of substrates utilized by microorganisms at different degrees, thereby inducing different degree of carbon accumulation and turnover in these size fractions (Kandeler et al., 2002). The aggregates distributions along soil vertical profile vary with ambient conditions and resources, thus influence microbial population and community composition (Eilers et al., 2012; Fierer et al., 2010). For example, studies have shown that enzyme activities related to $C$ decomposition are higher in macroaggregates, and organic carbon concentration in microaggregates is generally higher than that of macroaggregates (Qin et al., 2010; Nie et al., 2014). Soil water content is the primary control on how soil structure changes with depths in the soil profile. Soil $C$ is mainly correlated with macroaggregates in the surface soil as a substrate supply (Mandiola et al., 2011). Limited oxygen diffusion in aggregates generate hotspots coexisting with the anoxic and oxic microbes (Long and Or, 2005; Ebrahimi and Or, 2016). According to the hierarchical theory of aggregate formation, these elements are distributed unevenly in different aggregates size fractions and strongly related with aggregates stabilities (Six et al., 2004). The quality and quantity of nutrients in aggregates with different sizes along the soil profile are likely the driving factors regulating the nature and properties of the residing microbial communities (Or et al., 2007; Vos et al., 2013; Ebrahimi and Or, 2016).

Soil water content not only varies over depth in soil profile but also manipulates soil pore structure associating with dryingrewetting process, which conspires to limit nutrients (including oxygen and other gases) diffusion into (and out from) aggregates that generate hotspots accommodating microbial populations (Wang and Or, 2013; Ebrahimi and Or, 2016). These processes are even highlighted among rapidly waterfluctuating soil, e.g., sandy soil (typically the sandy-clay transition layers). Sandy soil is characterized by poor fertility due to the low water-holding capacity and constriction of root growth in the subsoil. Most researches on sandy soils have ignored the often dense and barely permeable clay layer where water and nutrients could be stored while hardly plant roots develop as compared with topsoil (Acosta-Martínez et al., 2010; Martirosyan et al., 2013; Sradnick et al., 2013). These harsh conditions likely exert environmental stresses on soil microbial communities, enabling niche differentiations. Therefore, we investigated soil microbial diversity and functional patterns and their associations with the characteristics of sandy soil profiles typically crossing sandy-clay layers' transition profile. Soil aggregate fractions and microbial community characteristics, as well as key nutrient indices across soil depth were quantified to determine the main influencing factor on changes of soil microorganisms. Microbial functions were evaluated by using Functional Annotation of Prokaryotic Taxa (FAPROTAX) and Phylogenetic Investigation of Communities by Reconstruction of Unobserved States (PICRUSt). We hypothesized that smallsize aggregates fractions instead of environmental properties regulated the microbial community compositions and that diversities distributed heterogeneously in soil profile. We also hypothesized that microbial interactions would form different ecological niche under different precipitation, and that niche differentiation would occur in deeper layers as well as that the associated microbial functions were due to the resource availability and environmental stress.

\section{Materials and methods}

\subsection{Site description and soil sample collection}

Soil samples were taken separately from three croplands in 
Lishu County of Jilin Province $\left(123^{\circ} 45^{\prime} \mathrm{E}, 43^{\circ} 02^{\prime} \mathrm{N}\right.$, LS), Langfang City of Hebei Province $\left(116^{\circ} 38^{\prime} \mathrm{E}, 39^{\circ} 28^{\prime} \mathrm{N}, \mathrm{LF}\right)$, and Zhengzhou City of Henan Province $\left(112^{\circ} 42^{\prime} \mathrm{E}, 34^{\circ} 16^{\prime} \mathrm{N}\right.$, ZZ), three kinds of typical sandy soil (according to Chinese Soil Texture Classification) of unirrigated agricultural lands with the average annual precipitations of $490 \mathrm{~mm}, 555 \mathrm{~mm}$ and $662 \mathrm{~mm}$ in LS, LF and ZZ, respectively. The average annual temperatures are $6.4^{\circ} \mathrm{C}, 11.9^{\circ} \mathrm{C}$ and $14.3^{\circ} \mathrm{C}$ in LS, LF and $Z Z$, respectively. The cropping systems are continuous maize in LS and $Z Z$ and wheat/maize rotation in LF. These three sampling sites formed an increasing gradient in average annual precipitation and temperature, but had similar profile pattern and cropping system. Field area in each sampling site was about $300 \mathrm{~m}^{2}(30 \mathrm{~m} \times 10 \mathrm{~m})$. Soil samples were collected from the top down to a clay layer $(>80 \mathrm{~cm})$ and separated as follows: topsoil $(0-20 \mathrm{~cm})$, rooted zone beneath the plough layer $(40-50 \mathrm{~cm})$ and clay-layer soils $(80-100 \mathrm{~cm})$. Five composite soil samples from each depth were collected at each sampling site in May 2016, and each soil sample was taken by mixing ten adjacent soil cores on each depth of each plot. The combined soil samples were immediately placed in ice bag and sent to laboratory for further analysis of their environmental properties characterization and molecular biology. To this end, they were divided into two aliquots and stored at $4^{\circ} \mathrm{C}$ and $-80^{\circ} \mathrm{C}$ respectively.

\subsection{Soil properties and aggregate fractions}

To determine soil water content of each sample, five-gram soils were weighed and placed in an oven (101-00BS, China) at $105^{\circ} \mathrm{C}$ for $24 \mathrm{~h}$. Soil organic matter (OM) was measured by potassium dichromate oxidation methods (Nelson and Sommers, 1982). Total nitrogen (TN) and total phosphorus (TP) were quantified through combustion in a Thermo Scientific FLASH 2000 NC Analyzer (Vario EL III, Elementar, Germany). Soil available potassium (AK) was extracted with $\mathrm{NH}_{4} \mathrm{OAc}$ and determined using a flame photometer (M425, Sherwood, England) (Bao, 2000).

50-gram soils were wet-sieved using the method modified from Six et al. (2000) to determine the water-stable aggregate proportions. Briefly, soil sample was first placed on a $1 \mathrm{~mm}$ sieve and slaked by submersion in deionized water for $5 \mathrm{~min}$. The sieve was then gently moved up and down for $10 \mathrm{~min}$. Remaining materials on sieve were rinsed into containers, while materials passing through $1.00 \mathrm{~mm}$ sieve mesh were transferred to $0.50 \mathrm{~mm}, 0.25 \mathrm{~mm}$ and $0.053 \mathrm{~mm}$ sieves in turn for further fractionation, ultimately generating five aggregate fractions $(>1.00 \mathrm{~mm}, 0.50-1.00 \mathrm{~mm}, 0.25-0.50 \mathrm{~mm}, 0.053$ $0.25 \mathrm{~mm},<0.053 \mathrm{~mm})$. Each fraction was dried $\left(105^{\circ} \mathrm{C}\right)$ and weighed, then used to determine proportions of macro$(\geqslant 0.5 \mathrm{~mm})$ and microaggregates $(<0.5 \mathrm{~mm})$ in soils.

\subsection{DNA extraction and sequence processing}

According to the manufacturer's instruction, $0.5 \mathrm{~g}$ freezingdried soil was used to isolate total DNA with a FastDNA Spin
Kit for Soil (MPBIO Laboratories Inc., CA, USA). The concentration and quality of extracted DNA were examined and determined through the absorption of DNA at $260 \mathrm{~nm}$ using a NanoDrop ${ }^{8}$ ND-2000c UV-Vis spectrophotometer (NanoDrop Technologies, Wilmington, DE, USA). Then all the extracted DNA samples were stored under $-80^{\circ} \mathrm{C}$ for further molecular biology analysis. The $\mathrm{V} 3+\mathrm{V} 4$ region of bacterial 16S rRNA gene was amplified with the primers barcoded515F (GTGCCAGCMGCCGCGGTAA) and 806R (CCCCGYCAATTCMTTTRAGT), traditionally used by the Earth Microbiome Project (EMP). PCR reactions performed in a $50 \mu \mathrm{L}$ mixture containing $25 \mu \mathrm{L}$ Premix Ex Taq (Takara Biotechnology), $5 \mu \mathrm{L}$ of each primer $(2 \mu \mathrm{M}), 2 \mu \mathrm{L}$ of diluted template DNA (1-10 ng) and $13 \mu \mathrm{L}$ sterilized water. Thermal-cycling conditions were listed as follows: an initial denaturation of 3 min at $94^{\circ} \mathrm{C}$, six touchdown cycles of $45 \mathrm{~s}$ at $94^{\circ} \mathrm{C}, 60 \mathrm{~s}$ from $65^{\circ} \mathrm{C}$ to $58^{\circ} \mathrm{C}, 70 \mathrm{~s}$ at $72^{\circ} \mathrm{C}$, followed by 22 cycles of $45 \mathrm{~s}$ at $94^{\circ} \mathrm{C}, 60 \mathrm{~s}$ at $58^{\circ} \mathrm{C}, 60 \mathrm{~s}$ at $72^{\circ} \mathrm{C}$ with a final elongation of 10 $\min 72^{\circ} \mathrm{C}$. PCR products were purified using a Wizard SV Gel and PCR Clean-up system (Promega, San Luis Obispo, CA, USA). Concentrations of PCR products were fluorometrically quantified by Qubit dsDNA HS Assay Kit (Invitrogen, Carlsbad, CA, USA) before being sequenced on the Miseq platform (Illumina, San Diego, CA, USA) at Novogene, Beijing, China.

\subsection{Bioinformatics analysis}

Raw sequences were processed in QIIME 1.7.0 (Caporaso et al., 2010). The reads that could not be assembled were removed, so did the chimeric reads. Sequences were quality trimmed and clustered into operational taxonomic units (OTUs) at a $97 \%$ identity threshold using UCLUST (Edgar, 2010). Taxonomic assignment was carried out through OTU with the RDP Classifier (Wang et al., 2007). Alpha diversity was characterized by richness (Shannon index) and evenness (Pielou index). Beta diversity was evaluated by calculating the Bray-Curtis distances. The Miseq sequencing data are available online (http://www.ncbi.nlm.nih.gov/geo/). The accession number for the MiSeq data is SRR9098510SRR9098555.

\subsection{Construction and characterization of phylogenetic molecular ecological networks}

Network analysis can evaluate the ecological interaction patterns among microbial species in different environments (Ma et al., 2016; Jiang et al., 2017; Sung et al., 2017). The dominant species were often regarded as functionally important species in a community (Smith and Knapp, 2003). In ecosystem, dominant taxa were thought to be more functionally important than other taxa (Walker et al., 1999). Keystone species in a network are important microbes that may lead to a dramatic change of an ecosystem once removed (Ze et al., 2013), which were often defined by the degree of node-specific interactions for taxa within microbial 
networks (Fisher and Mehta, 2014). Constructing and analyzing the microbial network provide a deeper understanding of microbial communities at various circumstances, particularly the interrelationships between different species.

Microbial interaction networks constructed based on $16 \mathrm{~S}$ rDNA sequencing data were defined as phylogenetic molecular ecological networks (Deng et al., 2012a). OTUs (at $97 \%$ sequence identity) occurring in $80 \%$ of the total samples were applied for network computation. The correlation between two detected microorganisms was measured by Spearman correlation coefficient ( $r$ value). Only the similarity values higher than a specific threshold were kept for calculating matrix eigenvalues. To allow comparison, an identical cut-off of 0.90 was used to construct the interaction networks. Positive associations in networks indicated common preferred environmental conditions, interspecies cross-feeding, coaggregation or niche overlapping, whereas the negatives suggested competition, niche partitioning or resistance to be grazed by predator in a food web (Deng et al., 2016). The network construction and statistical analysis were performed using the existing pipeline available at http://ieg4.rccc.ou.edu/ mena (Deng et al., 2012b).

OTUs within a module are highly connected among themselves but have less connections with OTUs outside the group. Species within the same module are considered to have the same niche. Modularity $(\mathrm{M})$ demonstrated a network which could be naturally divided into communities or modules. Random networks were used to evaluate whether the constructed networks were random, with the number of nodes and links being constant between random and experimental networks (Deng et al., 2012b). According to the within-module connectivity $\left(Z_{i}\right)$ and among-module connectivity $\left(P_{i}\right)$, four topological roles of nodes were classified: (a) peripheral nodes $\left(Z_{i} \leqslant 2.5, P_{i} \leqslant 0.62\right)$, always linking to the nodes within their modules; (b) connectors $\left(Z_{i} \leqslant 2.5\right.$, $P_{i}>0.62$ ), highly linking to several modules; (c) module hubs $\left(Z_{i}>2.5, P_{i} \leqslant 0.62\right)$, which have a few links to many nodes in their own modules; and (d) network hubs $\left(Z_{i}>2.5, P_{i}>0.62\right)$, which act as both module hubs and connectors.

\subsection{Ecological and statistical methods}

The results in our study are shown as mean value, and statistical significance is accepted at ${ }^{*} P<0.05,{ }^{*} P<0.01$ and ${ }^{* * *} P<0.001$. Pearson correlation analysis was used to assess the correlations between soil properties and soil microbial communities using SPSS 25. Based on the normalized resample OTU table of $16 \mathrm{~S}$ rRNA gene, we obtained alpha diversity (Shannon index), canonical correlation analysis (CCA), function annotation for 16S rRNA gene by using FAPROTAX (Louca et al., 2016) and PICRUSt (Langille et al., 2013). A one-way ANOVA was used to identify significant changes in soil properties and microbial community diversities. Permutation multivariate analysis of variance (PerMANOVA) was used to evaluate the significant change of microbial community compositions based on Bray-Curtis dissimilarity matrices between top and clay-layer soils. $R$ (version 3.5.2) was used in data processing and statistical analysis. Network analysis was performed to visualize the changes of microbial interactions, and mantel test was to evaluate the effect of environmental elements on microbial communities and interactions. The networks were visualized with Cytoscape 3.6.1.

\section{Results}

3.1 Soil aggregates and environmental properties distribution along soil profile

The distribution of soil aggregate size fractions was depicted in Fig. 1. In general, microaggregates $(<0.5 \mathrm{~mm}$ ) dominated in all three samples, with macroaggregates $(\geqslant 0.5 \mathrm{~mm})$ accounting for $11.2 \%-14.93 \%$ and $13.17 \%-19.9 \%$ for the top- and clay-layer samples, respectively. Specifically, $0.25-$ $0.5 \mathrm{~mm}$ aggregates dominated in LS samples, comprising $47.16 \%$ and $31.96 \%$ of the total aggregates in the top- and clay-layer soils, respectively. As for the ZZ samples, aggregates of $0.053-0.25 \mathrm{~mm}$ were the most abundant group, occupying $47.95 \%$ and $42.85 \%$ in total aggregates in the topand clay-layer soils, respectively. Microaggregates (0.053$0.25 \mathrm{~mm}$ and $<0.053 \mathrm{~mm}$ ) were of the majority for the LF samples, accounting for $35.27 \%$ and $43.82 \%$ in the top-layer soils, and $39.31 \%$ and $36.49 \%$ in the clay-layer soils, respectively.

In the top-layer soils, water content (W) was $4.25 \%, 5.84 \%$ and $6.17 \%$ for the LS, LF and ZZ samples, respectively (seeing in Supplementary Fig. S1). Water content in the deeper-layer soils at LS and LF remained nearly unchanged as compared with those top-layer ones, while decreased from $6.17 \%$ to $3.56 \%$ for the $\mathrm{ZZ}$ samples. The organic matter (OM) reached at the highest value of $11.15 \mathrm{~g} \mathrm{~kg}^{-1}$ in the deeperlayer soils from ZZ, followed by the LS samples of $5.45 \mathrm{~g} \mathrm{~kg}^{-1}$ and LF ones of $5.33 \mathrm{~g} \mathrm{~kg}^{-1}$. Total nitrogen (TN) content seemed stable in LS and ZZ profiles, while significantly decreased from top- to clay-layer soils. The mean TN content in LF soil was $0.50 \mathrm{~g} \mathrm{~kg}^{-1}$, about $64 \%$ and $4 \%$ higher than those in LS and ZZ soils. Soil total phosphorus (TP) declined with soil depth in all three sites with the lowest value of $1.1 \mathrm{~g} \mathrm{~kg}^{-1}$ in the clay-layer soil from LF. The average values of soil available potassium (K) were 133.27, 113.33 and $93.62 \mathrm{mg} / \mathrm{kg}^{-1}$ in LF, LS and ZZ, respectively. The TN value significantly correlated with aggregates at size of 0.25 $0.5 \mathrm{~mm}(r=-0.499, P<0.05)$, and the TP value with aggregates of $0.25-0.5 \mathrm{~mm}(r=0.589, P<0.01)$ and $<0053 \mathrm{~mm}(r=-0.441, P<0.05)$.

\subsection{Variation of bacterial community compositions and diversity patterns}

The RDP classifier with a threshold of 0.5 was applied to identify the dominant bacterial sequences to differentiate 

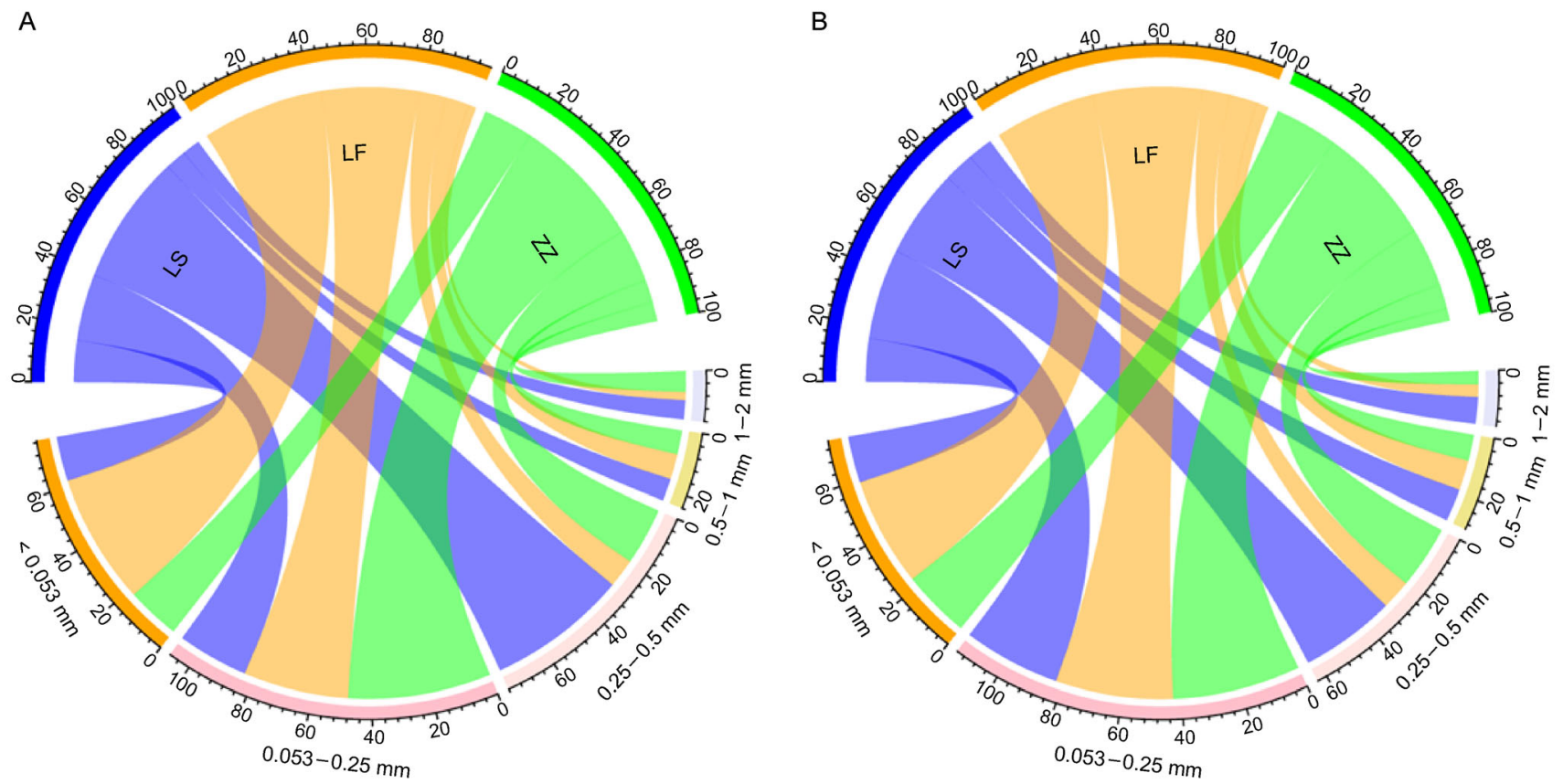

Fig. 1 Distribution of soil aggregate size fractions between surface (A) and clay-layer (B) in three sampling sites. LF: Langfang City (yellow); LS: Lishu County (blue); ZZ: Zhengzhou City (green).

phylogenetic bacterial taxa levels. The relative abundances of bacteria at the phylum and class levels between top and claylayer soils from sampling sites were listed in Fig. 2. The results indicated Proteobacteria, Actinobacteria, Thaumarchaeota, Acidobacteria, Bacteroidetes, Chloroflexi, Planctomycetes and Firmicutes were the most superior phyla, accounting for $\geqslant 85 \%$ of the total sequences (Fig. 2A). Generally, Proteobacteria dominated bacterial communities with the abundance of $23.3 \%$ and $21.41 \%, 19.54 \%$ and $23.67 \%, 22.34 \%$ and $24.5 \%$ between top- and clay-layer from LS, LF and ZZ soils, respectively. Firmicutes was more abundant in LS than that in LF and ZZ soils, while contrary tendency was observed in Thaumarchaeota. Actinobacteria and Acidobacteria showed no significant changes between top- and clay-layer soils from three sampling sites. The relative abundance of Proteobacteria $(r=-0.832, P<0.05)$ and Crenerchaeota $(r=0.814$, $P<0.05)$ significantly correlated with the TN value, and Actinobacteria $(r=-0.884, P<0.05)$ was strongly affected by the $\mathrm{OM}$. The relative abundance of Acidobacteria strongly correlated with aggregates at size of $0.5-1 \mathrm{~mm}$ (Table 1) in the top-layer soils. Crenerchaeota and Firmicutes had significant relationship with aggregates at size of 0.053 $0.25 \mathrm{~mm}$ and $>1 \mathrm{~mm}$ in the clay-layer soils, respectively. Actinobacteria was obviously influenced by aggregates at size of $0.5-1 \mathrm{~mm}$ in the top-layer and $0.25-0.5 \mathrm{~mm}$ in the clay-layer soils. The most abundant class was Actinobacteria (Fig. 2B) with the range of $11.93 \%-14.85 \%$ and $12.84 \%$ $14.38 \%$ in top- and clay-layer soils, respectively. The relative abundances of Chloroplast and Bacilli were higher in LS than those in LF and ZZ. LS had the highest abundance of Betaproteobacteria (6.53\%) in topsoil and the lowest abundance of Alphaproteobacteria (6.39\%) in clay-layer soil.
PERMANOVA analysis revealed that the bacterial communities for the $Z Z$ soils differed significantly between the topand clay-layer soils $(P<0.05)$. In addition, mantel tests and canonical correlation analysis (CCA) were performed to investigate the relationship between environmental attributes and the structure of microbial communities. Mantel tests based on Bray-Curtis distances demonstrated that OM was significantly correlated with bacterial communities for the $\mathrm{ZZ}$ soils (Fig. $3 C$ ). The first two canonical axes explained $11.37 \%$, $27.51 \%$ and $29.2 \%$ of the microbial communities from the LS, LF and ZZ soils, respectively. No significant change in diversity and evenness were observed within soil profiles in three sampling sites, in terms of Shannon index and Pielou evenness (Supplementary Fig. S2). Shannon index value of bacterial communities for the LF soils ranged at 5.83- 6.30, which was higher than those of the LS and ZZ soils. The highest Shannon index values of top-layer (6.86) and claylayer (7.03) soils were observed in the ZZ soils, while the LF soils hosting the lowest Pielou index values in both the toplayer ( 0.77$)$ and clay-layer ( 0.84$)$ soils. A generally negative relationship was found between the Shannon index value and the percentage of aggregates under $0.053 \mathrm{~mm}$ for the claylayer soils yet the top-layer soils (Table 2 ).

\subsection{Soil microbial communities and interaction patterns among sampling sites}

The co-occurrence ecological network constructed by OTUs in different modules was depicted in Fig. 4. One module suggested that the microbial communities within it should have similar ecological niches. Hence, the soil microbial taxa in LS were grouped into eight major ecological clusters 


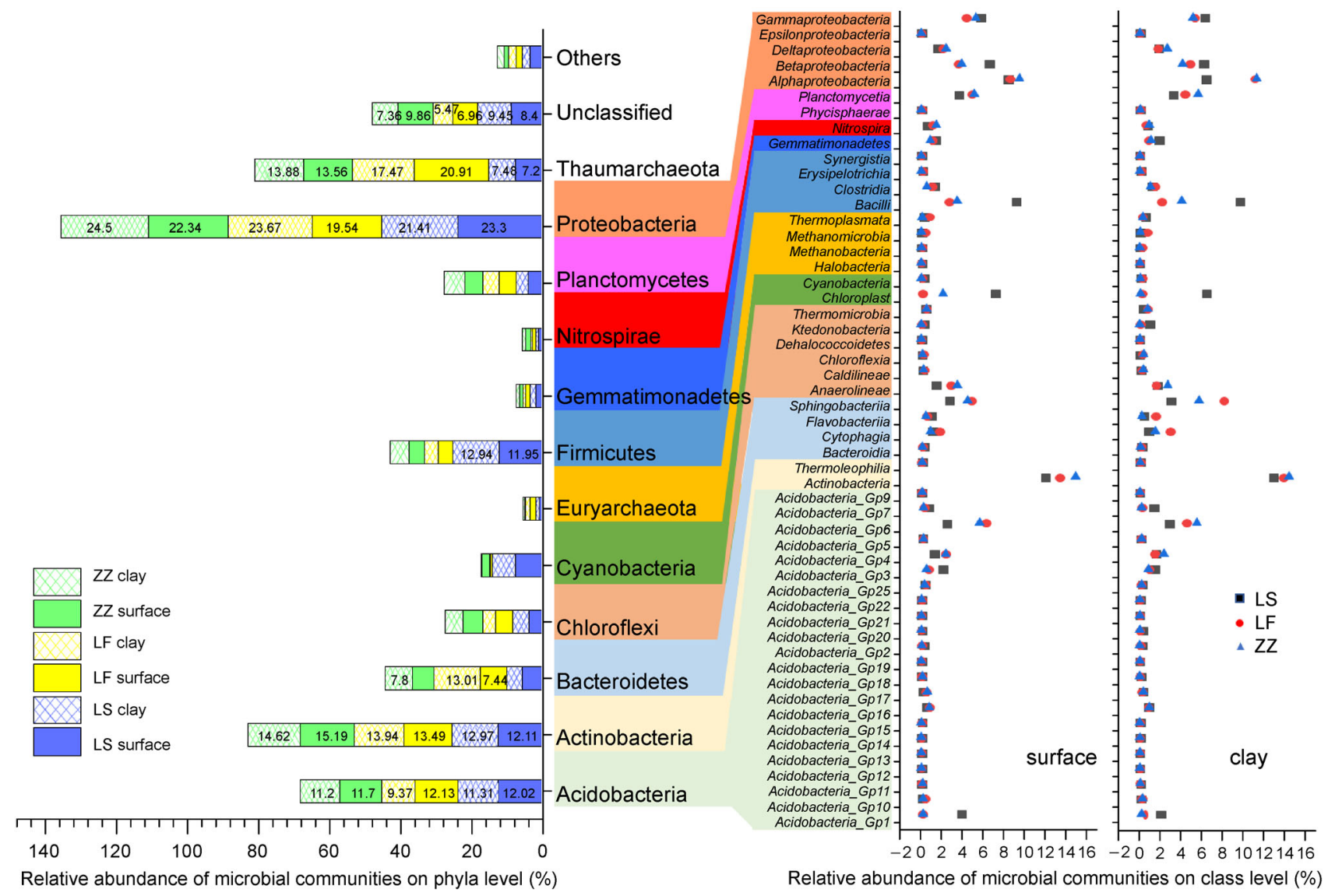

Fig. 2 Relative abundances (\%) of microbial communities (phylum and class levels) across three sampling sites. The numbers shown in the bar plot (left) indicated the relative abundance of the corresponding phyla; Different pattern represented microbial community based on phylum level. LF: Langfang City; LS: Lishu County; ZZ: Zhengzhou City.

Table $1 P$ value of Pearson correlation between relative abundance of top 10 classified microbial phyla and aggregate size proportions of the topand clay-layer soils.

\begin{tabular}{|c|c|c|c|c|c|c|c|c|c|c|c|}
\hline $\begin{array}{l}\text { Soil } \\
\text { depth }\end{array}$ & $\begin{array}{l}\text { Aggregate } \\
\text { sizes }\end{array}$ & $\begin{array}{l}\text { Acidob- } \\
\text { acteria }\end{array}$ & $\begin{array}{l}\text { Actinob- } \\
\text { acteria }\end{array}$ & $\begin{array}{l}\text { Bacteroi- } \\
\text { detes }\end{array}$ & $\begin{array}{l}\text { Chlor- } \\
\text { oflexi }\end{array}$ & $\begin{array}{l}\text { Crenarch- } \\
\text { aeota }\end{array}$ & $\begin{array}{l}\text { Firmi- } \\
\text { cutes }\end{array}$ & $\begin{array}{l}\text { Gemmati- } \\
\text { mona- } \\
\text { detes }\end{array}$ & $\begin{array}{l}\text { Nitro- } \\
\text { spirae }\end{array}$ & $\begin{array}{l}\text { Plancto- } \\
\text { mycetes }\end{array}$ & $\begin{array}{l}\text { Proteobac- } \\
\text { teria }\end{array}$ \\
\hline \multirow[t]{5}{*}{ Topsoil } & $>1 \mathrm{~mm}$ & 0.462 & 0.412 & 0.691 & 0.797 & 0.920 & 0.707 & 0.627 & 0.414 & 0.649 & 0.591 \\
\hline & $0.5-1 \mathrm{~mm}$ & $0.022^{\mathrm{a}}$ & 0.029 & 0.868 & 0.762 & 0.479 & 0.267 & 0.932 & 0.855 & 0.910 & 0.968 \\
\hline & $0.25-0.5 \mathrm{~mm}$ & 0.105 & 0.155 & 0.742 & 0.636 & 0.353 & 0.140 & 0.806 & 0.981 & 0.784 & 0.842 \\
\hline & $0.053-0.25 \mathrm{~mm}$ & 0.615 & 0.665 & 0.232 & 0.126 & 0.157 & 0.370 & 0.296 & 0.509 & 0.274 & 0.332 \\
\hline & $<0.053 \mathrm{~mm}$ & 0.346 & 0.296 & 0.807 & 0.913 & 0.804 & 0.592 & 0.743 & 0.530 & 0.765 & 0.707 \\
\hline \multirow{5}{*}{$\begin{array}{l}\text { Clay- } \\
\text { layer } \\
\text { soil }\end{array}$} & $>1 \mathrm{~mm}$ & 0.233 & 0.283 & 0.614 & 0.508 & 0.225 & 0.013 & 0.678 & 0.891 & 0.656 & 0.714 \\
\hline & $0.5-1 \mathrm{~mm}$ & 0.669 & 0.719 & 0.178 & 0.072 & 0.211 & 0.424 & 0.242 & 0.455 & 0.220 & 0.278 \\
\hline & $0.25-0.5 \mathrm{~mm}$ & 0.079 & 0.028 & 0.925 & 0.819 & 0.536 & 0.324 & 0.989 & 0.798 & 0.967 & 0.975 \\
\hline & $0.053-0.25 \mathrm{~mm}$ & 0.482 & 0.533 & 0.365 & 0.259 & 0.024 & 0.237 & 0.429 & 0.642 & 0.407 & 0.465 \\
\hline & $<0.053 \mathrm{~mm}$ & 0.184 & 0.134 & 0.969 & 0.925 & 0.642 & 0.430 & 0.905 & 0.692 & 0.927 & 0.869 \\
\hline
\end{tabular}

a The bold ones indicate the significance of the relationship between microbial abundances and aggregate sizes distribution. 
A $\quad(F=0.993, p=0.338)$

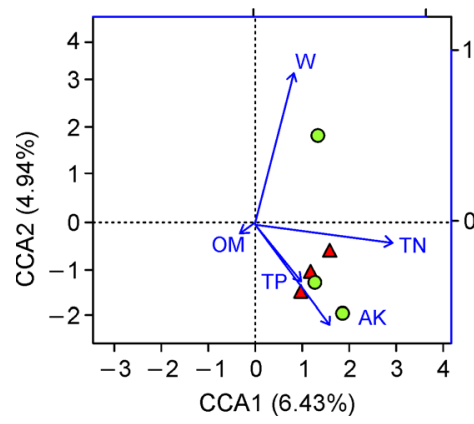

B

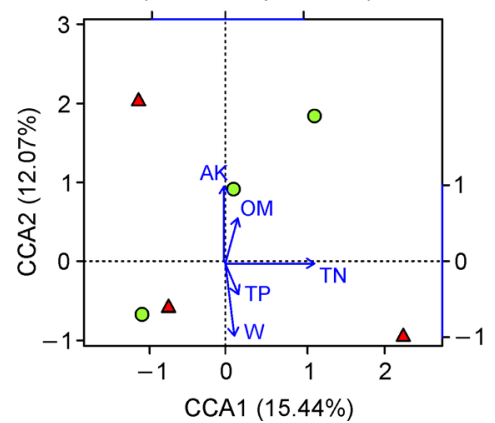

C

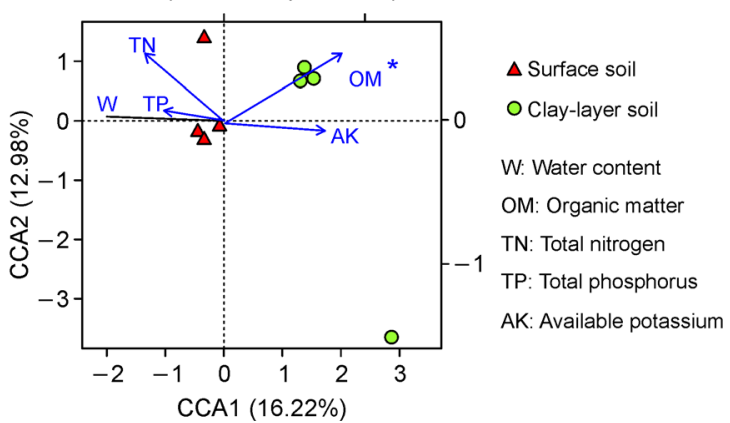

Fig. 3 Canonical correspondence analysis (CCA) plots of microbial community composition at the OTU level in three sampling sites (A: LS; B: LF; C: ZZ). LF: Langfang City; LS: Lishu County; ZZ: Zhengzhou City. Red triangles and green circles represented samples in surface and clay-layer soils, respectively. "*” indicated the environmental properties significantly affected the microbial community compositions analyzed by PERMANOVA ( $\left.{ }^{*} P<0.05\right)$.

Table $2 P$ value of Pearson correlation between microbial alpha-diversity and aggregate size proportions of the top- and clay-layer soils

\begin{tabular}{|c|c|c|c|c|c|c|c|c|c|}
\hline \multirow{2}{*}{$\begin{array}{l}\text { Soil } \\
\text { depth }\end{array}$} & \multirow{2}{*}{$\begin{array}{l}\text { Aggregate } \\
\text { sizes }\end{array}$} & \multicolumn{4}{|c|}{ Topsoil } & \multicolumn{4}{|c|}{ Clay-layer soil } \\
\hline & & Shannon & $\begin{array}{l}\text { Inv__ } \\
\text { Simpson }\end{array}$ & $\begin{array}{l}\text { Pielou_ } \\
\text { evenness }\end{array}$ & $\begin{array}{l}\text { Simpson_ } \\
\text { evenness }\end{array}$ & Shannon & $\begin{array}{l}\text { Inv__ } \\
\text { Simpson }\end{array}$ & $\begin{array}{l}\text { Pielou_ } \\
\text { evenness }\end{array}$ & $\begin{array}{l}\text { Simpson_ } \\
\text { evenness }\end{array}$ \\
\hline \multirow[t]{5}{*}{ Topsoil } & $>1 \mathrm{~mm}$ & 0.259 & 0.367 & 0.096 & 0.445 & 0.186 & 0.252 & 0.171 & 0.274 \\
\hline & $0.5-1 \mathrm{~mm}$ & 0.181 & 0.807 & 0.536 & 0.886 & 0.254 & 0.692 & 0.270 & 0.714 \\
\hline & $0.25-0.5 \mathrm{~mm}$ & 0.308 & 0.934 & 0.662 & 0.988 & 0.380 & 0.819 & 0.396 & 0.840 \\
\hline & $\begin{array}{l}0.053- \\
0.25 \mathrm{~mm}\end{array}$ & 0.818 & 0.556 & 0.828 & 0.478 & 0.890 & 0.671 & 0.906 & 0.650 \\
\hline & $<0.053 \mathrm{~mm}$ & 0.144 & 0.482 & 0.211 & 0.561 & 0.071 & 0.367 & 0.055 & 0.389 \\
\hline \multirow{5}{*}{$\begin{array}{l}\text { Clay- } \\
\text { layer } \\
\text { soil }\end{array}$} & $>1 \mathrm{~mm}$ & 0.436 & 0.939 & 0.790 & 0.860 & 0.508 & 0.946 & 0.524 & 0.968 \\
\hline & $0.5-1 \mathrm{~mm}$ & 0.872 & 0.502 & 0.774 & 0.424 & 0.944 & 0.617 & 0.960 & 0.596 \\
\hline & $0.25-0.5 \mathrm{~mm}$ & 0.124 & 0.750 & 0.479 & 0.829 & 0.197 & 0.635 & 0.213 & 0.657 \\
\hline & $\begin{array}{l}0.053- \\
0.25 \mathrm{~mm}\end{array}$ & 0.685 & 0.689 & 0.960 & 0.611 & 0.758 & 0.804 & 0.774 & 0.782 \\
\hline & $<0.053 \mathrm{~mm}$ & $0.019^{a}$ & 0.644 & 0.373 & 0.723 & 0.091 & 0.529 & 0.107 & 0.551 \\
\hline
\end{tabular}

a The bold ones indicate the significance of the relationship between microbial diversities and aggregate sizes distribution.

(modules) comprising of populations strongly co-occurring with each another (Fig. 4A), and the network structures in LF (Fig. 4B) and ZZ (Fig. 4C) were clustered into merely two modules. The networks became more clustered in terms of less nodes and more links in microbial networks from LS, LF to ZZ (Supplementary Table S1). Average connectivity (avgK) and edges were of the highest in the $\mathrm{ZZ}$ soils which had the least nodes. The nodes with higher connectivity are usually considered as key species, which occupies the central positions of the networks. The phylum of key species was significantly different among three sampling sites. Proteobacteria and Crenerchaeota dominated in LS and LF networks, respectively. These two phyla were both important in $\mathrm{ZZ}$ network structure. OTUs, belonging to Acidobacteria, had more complex interactions with the other phyla in the $\mathrm{ZZ}$ soils
(Fig. 4C), rather than those in LS and LF. The results from mantel test showed that soil properties had limited effect on soil microbial network, except for OM $\left(r=0.12,{ }^{* \star} P<0.01\right)$ and available $\mathrm{K}\left(r=0.117,{ }^{* *} P<0.01\right)$ in LF.

Topological roles of the OTUs identified are shown as a Z-P plot (Fig. 5). Generally, the majority of OTUs were peripherals, which were mainly linking species within their modules. Some of the peripherals from LS and ZZ even barely linked outside to their own modules $\left(P_{i}=0\right)$. While the proportion of module hubs functioned in connecting species within modules were of the highest in the $\mathrm{ZZ}$ networks (1.32\%) (Fig. 5C). Gemmatimonadetes Gemm-1 (OTU_30) and Bacteroidetes saprospirae (OTU_890) were two module hubs in the ZZ network (Fig. 5C). One module hub (OTU_77), belonging to Planctomycetes Planctomycetia, was found in the LS network (Fig. 
A

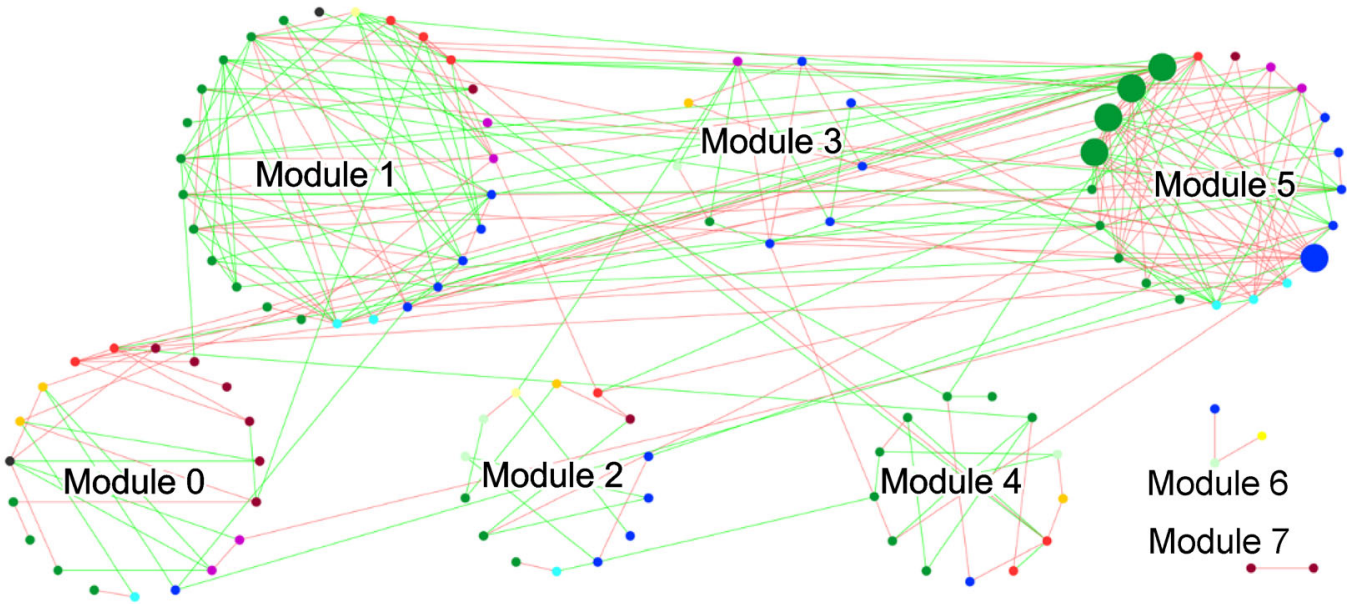

B

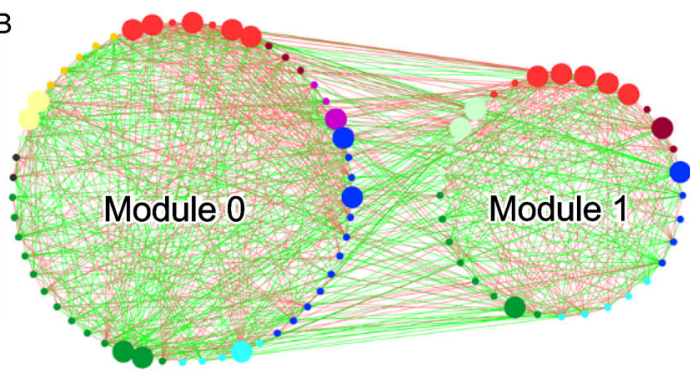

D

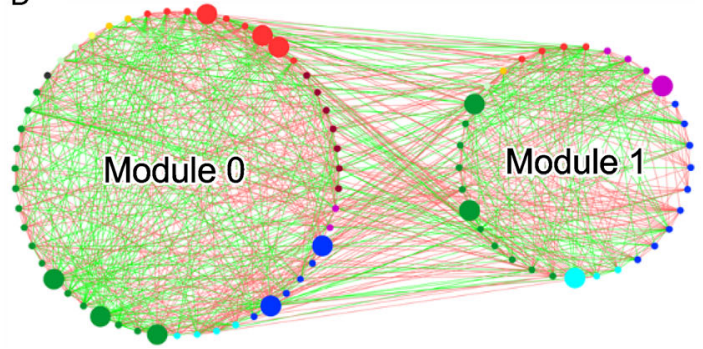

C
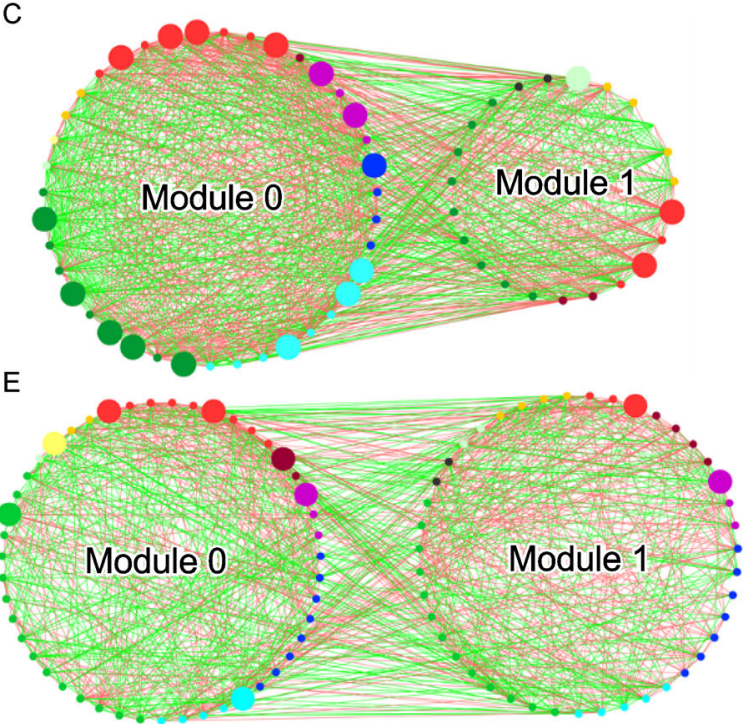

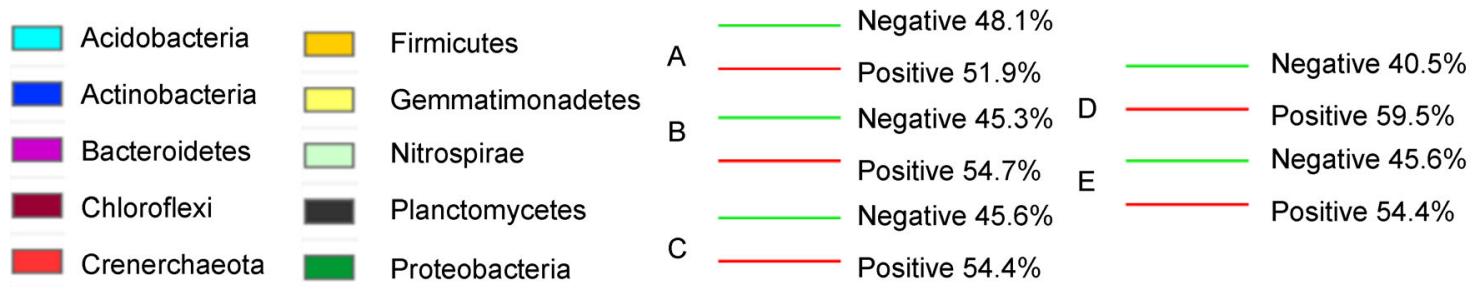

Fig. 4 The co-occurrence ecological network constructed by OTUs in different modules (A: LS; B: LF; C: ZZ; D: surface; E: clay layer). LF: Langfang City; LS: Lishu County; ZZ: Zhengzhou City. Each node represents an OTU, and the connectivity between two OTUs is indicated by the edges. Nodes colors signify different phylum. Bigger nodes represent the dominant taxa with a high degree of nodes. The red and green links indicate positive and negative correlation, respectively.

$5 A)$. Network structure of LS showed higher proportion of connectors linking to the other modules (5.56\%) (Fig. 5A). As for the LS soils, two of the six connector OTUs (OTU_11292 and OTU_235) were from Actinobacteria that were closely related to Actinobacteria and $M B-A 2-108$, respectively (Fig. 5A). The other four connectors were derived from
Crenarchaeota and Proteobacteria close to Thaumarchaeota and Alphaproteobacteria, respectively. Two connectors observed in the ZZ network (Fig. 5C) were from Acidobacteria Chloracidobacteria and Firmicutes Bacilli. No network hubs were detected out in all three networks. No module hubs and connectors were found in LF network. 
3.4 Changes of interaction patterns and key species along soi profile

Microbial taxa were specified into two modules in both top-

(Fig. 4D) and clay-layer soils (Fig. 4E), with Proteobacteria and Actinobacteria playing a more important role in the toplayer soils as compared to that of clay-layer soils. One module hub (OTU_2478), belonging to Bacteroidetes, was found in the clay-layer network (Fig. 5E). New network was reconstructed by selecting OTUs in both top- and clay-layer soils to better understand the interaction patterns among different phyla between top- and clay-layer soils (Fig. 6). Twelve modules were classified in microbial networks dominated by a positive correlation $(63.7 \%)$ between the top- and clay-layer soils (Fig. 6A). Specifically, species in module 7 had more complex interactions than the other modules, where Crenarchaeota occupied an important position and became more abundant in clay layer along with Proteobacteria. The Proteobacteria OTU number in the top-layer soils was significantly larger than that of the clay-layers in module 8 (Fig. 6B). The relative soil microbial abundance was at the similar level for the top- and clay-layer soils across all three sampling sites, except for Crenarchaeota which had higher abundance in the top-layer soils (Fig. 6C).

The global properties of empirical network indicated that OTU_11292 (Actinobacteria) and OTU_6 (Proteobacteria) played a dominant role in the microbial interactions in the topand clay-layer soils, respectively (Supplementary Table S1),
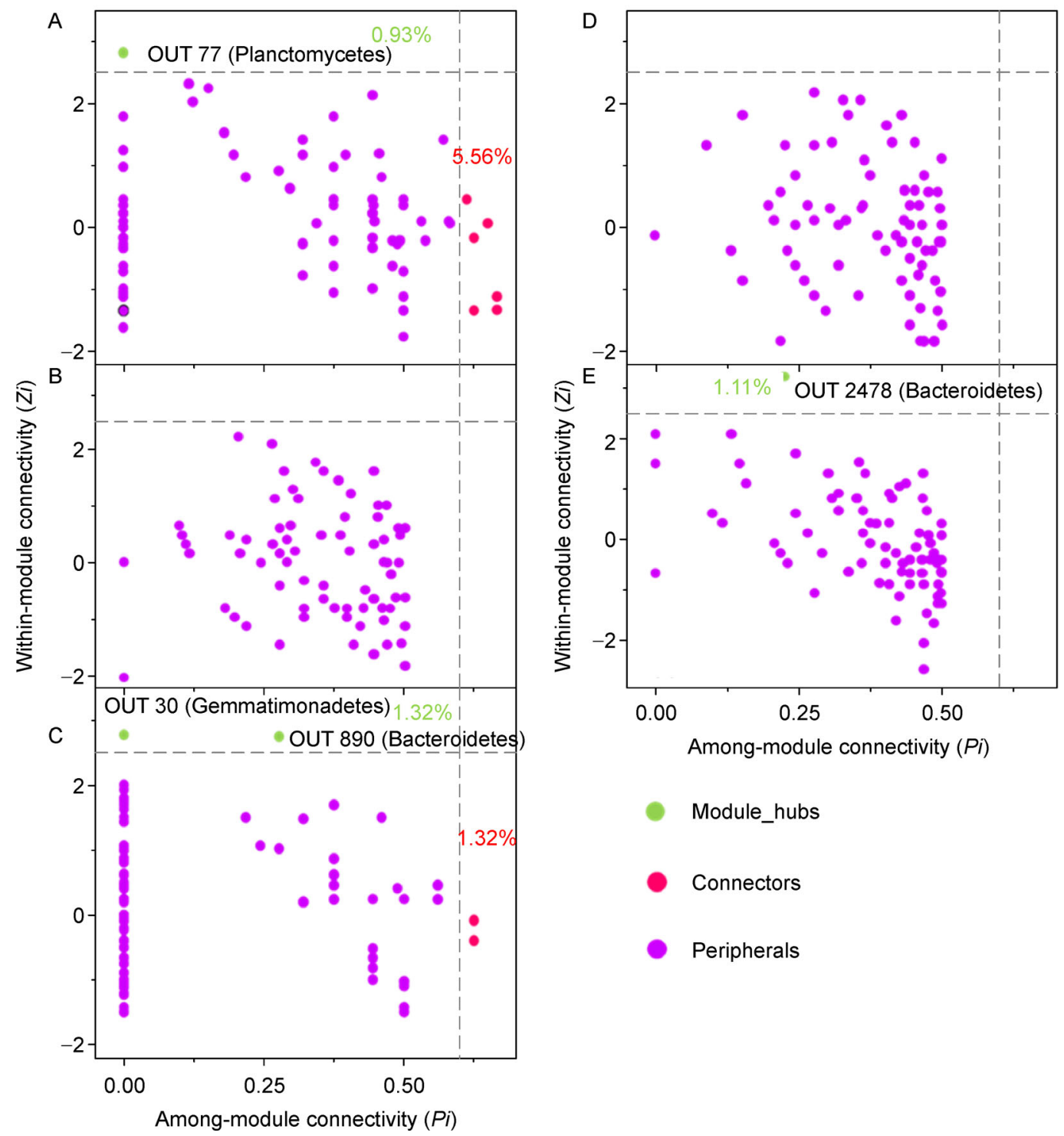

Fig. 5 Z-P plot exhibiting the distribution of OTUs based on the topological roles (A: LS; B: LF; C: ZZ; D: surface; E: clay layer). LF: Langfang City; LS: Lishu County; ZZ: Zhengzhou City. Each point represents an OTU. The location of each OTUs determined according to the withinmodule connectivity $(Z i)$ and among-module connectivity $(P i)$. The module hub is defined according to $Z i$ and $P i$ values $(Z i>2.5, P i \leqslant 0.62)$. The four identified module hubs were marked with OTU numbers and its phylum. 
A

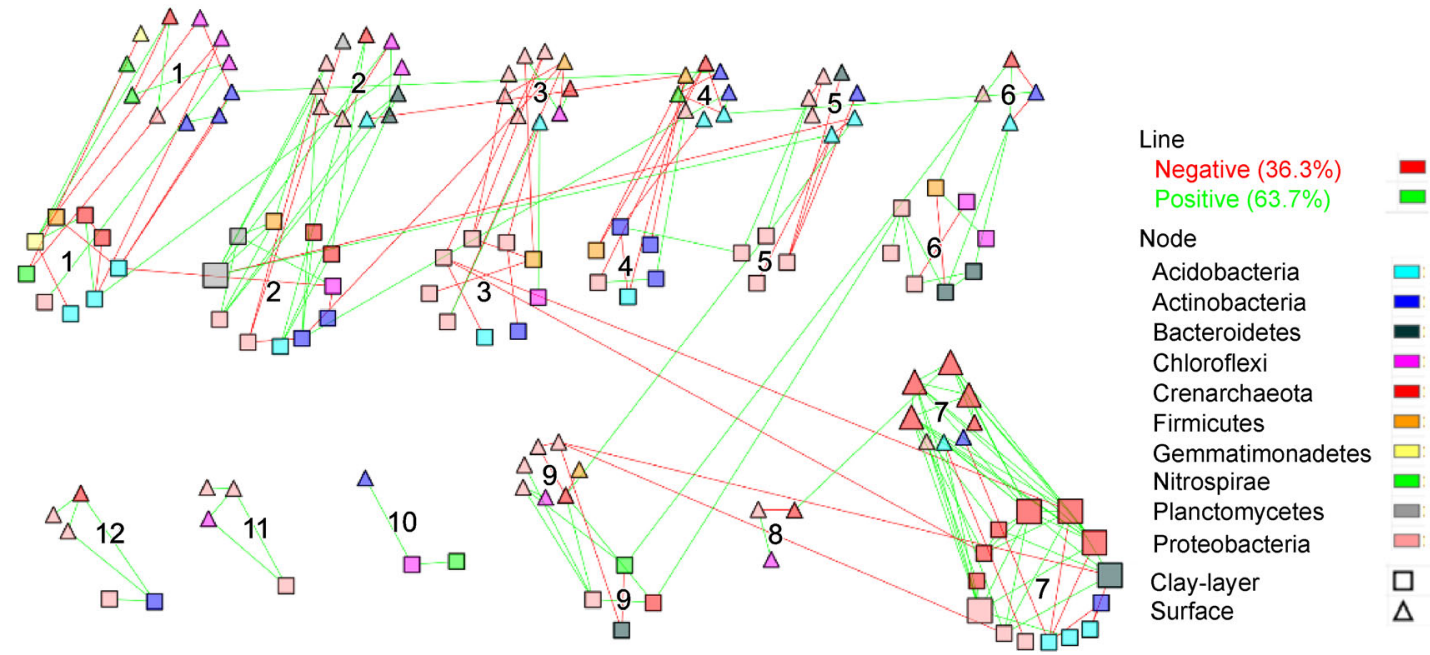

B

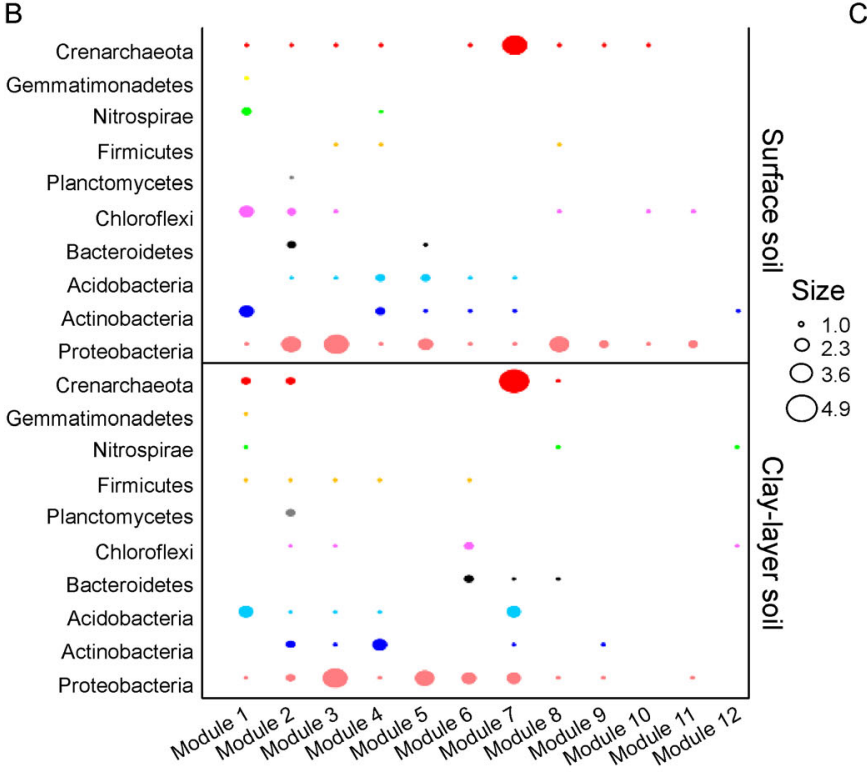

C

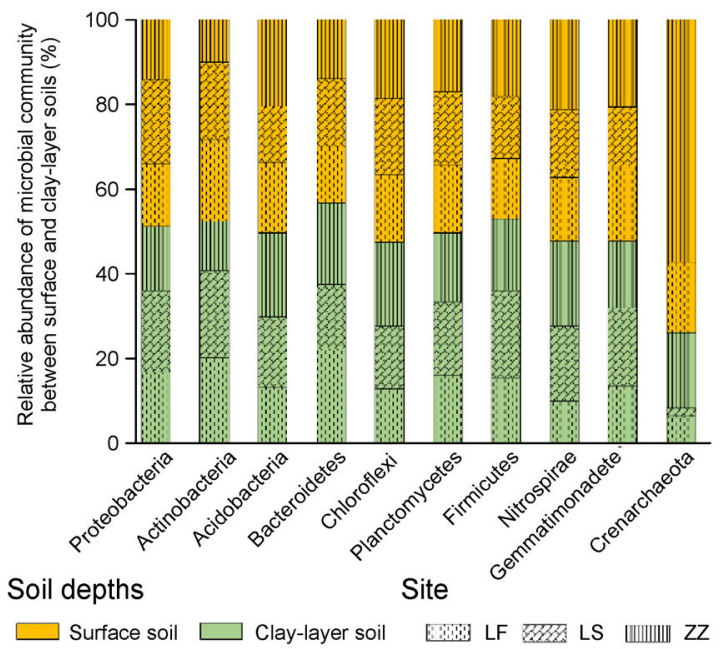

Fig. 6 Changes of microbial interaction between surface and clay layer soils. A:Reconstructed network by selecting OTUs in both surface and clay-layer soils; B: Differences in numbers of OTUs in phylum level; C: Distribution of microbial communities in phylum level between surface and clay layer soils among three sampling sites. The number of the network signify the module number. LF: Langfang City; LS: Lishu County; ZZ: Zhengzhou City.

evidenced by the maximum degree and eigenvector centrality. To better understand the microbial interaction patterns along soil profile, two new networks through selecting the first neighbors of OTU_11292 and OTU_6 in the top- and claylayer soils were visualized in Fig. 7A and 7B. In the top-layer soil, OTU_11292 and OTU_6 emerged in the same module, indicating the same ecological niche (Fig. 7A). While OTU_11292 transferred into the other module away from OTU_6 in the clay-layer soils (Fig. 7B), indicating that niche differentiation occurred in the deeper-layer soils. The reconstructed networks by selecting Proteobacteria and Actinobacteria showed that the clay-layer network had more negative correlations $(55.37 \%)$ as compared with that of the top-layer soils (37.3\%) (Fig. 7C and 7D). It indicated that the competition between Proteobacteria and Actinobacteria became stronger across the soil depth, causing decreased relative abundance. We also restructured network by selecting the first-neighbors of Proteobacteria and Actinobacteria to evaluate whether specific species contributed to such competitions (Fig. 7E and 7F). The results showed that Proteobacteria was more closely related with the other species (OTU) than Actinobacteria in both top- (Fig. 7E) and clay-layer soils (Fig. 7F). OTU_30 (Gemmatimonadetes Gemm-1) had more complex interaction with OTUs belonging to Crenerchaeota and Bacteroidetes in clay-layer network (Fig. 7H), and negatively correlated with OTU_2478 (the module hub that enhanced the connectivity within module) and a new species OTU_75. 
A

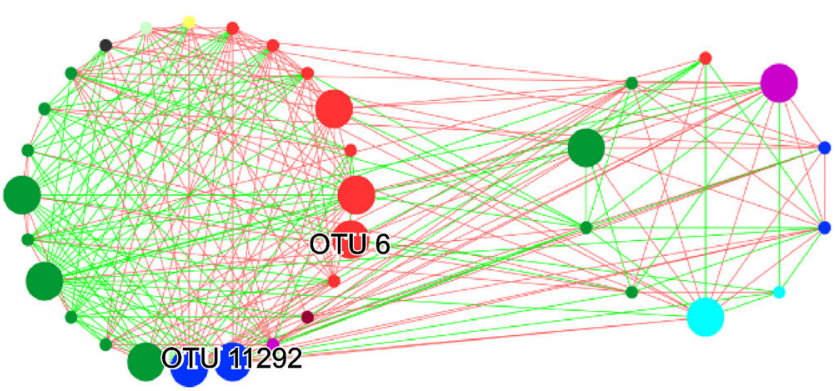

C

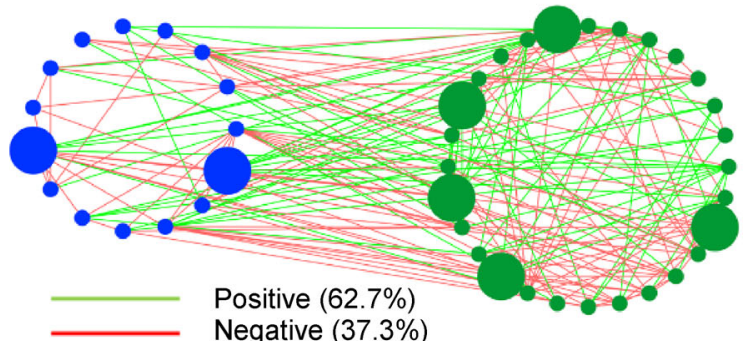

E

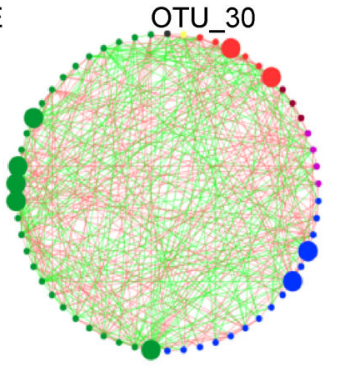

Acidobacteria

Actinobacteria
F

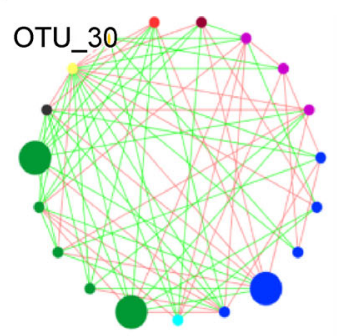

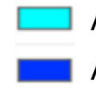

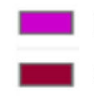

Bacteroidetes

Crenerchaeota

Chloroflexi

Firmicutes
B

Clay-layer
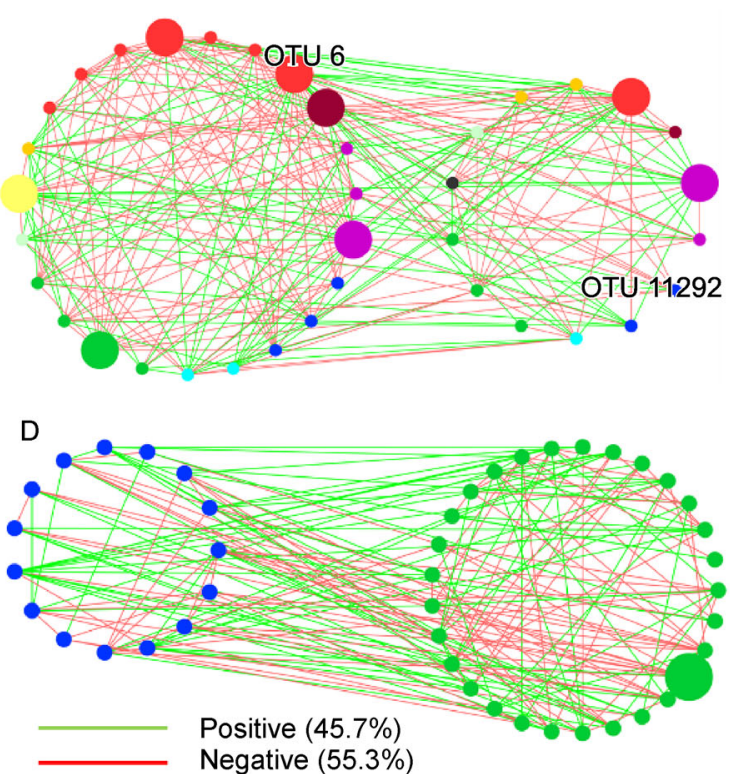

G

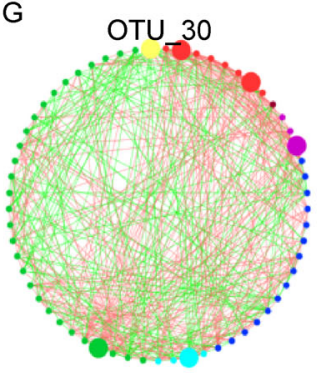

H

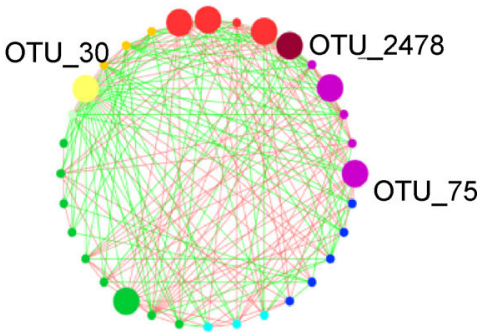

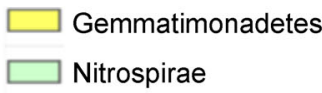

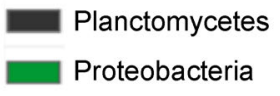

Fig. 7 The reconstruct network by selecting the first- neighbor of OUT_6 and OUT_11292 in surface (A) and clay-layer soils (B). Microbial network of surface and clay-layer soils based on the interaction between Proteobacteria and Actinobacteria (C-D). Restructured network by selecting the first neighbor of Proteobacteria and Actinobacteria, respectively (E-F) and OTU_30 (G-H) from surface and clay-layer soil networks, respectively.

3.5 Microbial function prediction between the top- and claylayer soils

FAPROTAX and PICRUSt were adopted to predict ecological and biological functions to the bacteria OTUs. A total of 53 categories were linked to the bacterial communities according to the FAPROTAX with the dominant functional groups $(>1 \%)$ being assigned as nitrification, aerobic ammonia oxidation, chemoheterotrophy, aerobic chemoheterotrophy and fermentation (Supplementary Fig. S3A). KEGG showed (Supplementary Fig. S3B) that the majority of predicted protein sequences was associated with the functions involved in metabolism $(44.34 \%-44.93 \%)$, genetic information processing (16.23\%-16.90\%), environmental information processing $(12.86 \%-13.57 \%)$, organismal systems $(7.40 \%-7.72 \%)$ and cellular processes $(3.23 \%-3.83 \%)$.

\section{Discussion}

In this study, the changes of environmental properties, microbial community composition and functional networks between top- and clay-layer soils were mainly driven by niche differentiation typically in available nutrient resources and other environmental characteristics (Smith et al., 2014). Significant correlations between TN and TP and aggregates observed in this study also confirmed that different distributions of soil aggregates along soil profile directly contributed to manipulating the processes of nutrient movements. The TP significantly declined from top- to clay-layer soils in all three sampling sites, and the OM strongly decreased from the topto clay-layer soils sampled in LS and LF. The relative abundance of microbial community in phylum level was highly 
related to aggregates proportion in the clay-layer soils, rather than that of the top-layer soils in this study, likely due to the differences in available nutrients between the top- and claylayer soils. The clearly different soil aggregates distributions diversified the environmental characteristics along soil profile and thereby, variable resources availability and niches differentiation for hosting the large variety of microbial communities (Bending et al., 2004).

In addition, aggregate distribution directly contributed to manipulating the processes of water evaporation, pore-size configuration in soil profile, which conspired to determine resources and physical niches availability to the residing microbial populations. The top-layer soils often experienced more frequently varying water configuration as compared with the relatively stable ones in the deeper-layer (clay-layer) soils. This might induce changes of resources availability and other environmental characteristics (to the hosting microbes) across soil profile, hosting distinctly functioning microbial communities. Soil water content might be partially responsible for the differentiation of microbial communities with depth in sandy soil. Studies had showed that variability in soil moisture could influence both bacterial and fungal community compositions (Brockett et al., 2012; Li et al., 2017). Our results showed that the dominant phyla in microbial networks differed between the top- and clay-layer soils, with a negative correlation being stronger in the clay-layer soils, which was most likely attributed to the OTU_30 that belongs to Gemmatimonadetes Gemm-1. Gemmatimonadetes was often inversely correlated to moisture (Bowen et al., 2012), indicating that microbial groups specialized for deeper soils had a high tolerance for moisture stress and the variation of microbial networks were associated with the water content between the top- and clay-layer soils. While the soil water content did not vary appreciably or the variability was much higher at the top-layer soils than those of deeper-layer ones (Supplementary Fig. S1), suggesting that the moisture within aggregates to be a driving force regulating microbial community compositions and functions. Therefore, it is confident that microenvironment induced by soil aggregates distribution profoundly affects the compositions and interactions of microbial communities, with the resources availability being of a key factor responsible for the changes of microbial communities through soil profile.

Aggregates comprise the microenvironment where the physical properties (water holding capacity, structural stability) and chemical properties (cation exchange capacity, organic matter content and quality) were different among those of different sizes. Microaggregates $(0.053-0.25 \mathrm{~mm})$ were more abundant in clay-layer soils than those top-layer ones, and microbial relative abundance was tightly related to the aggregate proportions typically in the clay-layer soils yet the top-layer ones. It suggested that the microaggregates to be more beneficial to microbial growth. Difference in soil OM quality within aggregate fractions diversified substrates availability in situ, which directly contributed to the nature of microbial community patterns (Bending et al., 2004). Aggregate fraction with different sizes formed different pore networks through soil profile and induced difference in nutrient availability and water retention at soil depth. Petersen et al. (2016) found that pore-size distribution systematically affects soil water retention. Microbial communities were shaped partly by different resources and environmental conditions within different aggregate sizes. The resources composition and availability in microaggregates were considered to be more favorable for microbes to utilize than those in macroaggregates, even though the later ones often had higher resource content (Mummey et al., 2006; Davinic et al., 2012). Studies revealed that soil OM in microaggregates with higher $\mathrm{OC}$ and $\mathrm{N}$ concentrations may have higher turnover rate and thereby, having a stronger selectivity for microbial community pattern as compared with macroaggregates (Cheng et al., 2011; Davinic et al., 2012; Nie et al., 2014). The results observed that the alpha-diversity of soil microbial communities was obviously correlated with microaggregates proportion $(<0.053 \mathrm{~mm}$ ) in clay-layer soils, evidencing that resources availability of microaggregates was a driving factor regulating microbial community patterns.

The results of microbial networks analysis provided some fresh information about the differences in microbial community interactions by evaluating distribution patterns of functional groups among different niche. The network complexity increased with soil water content, suggesting that favorable water content should support more stable and complex microbial network structure. Wang et al. (2018) also observed that microbial networks became more complex as the precipitation increases. Acidobacteria and Bacteroidetes were more abundant in $\mathbf{Z Z}$, supporting that these two phyla became more dominant at increased precipitation (Cho and Jang, 2014; Zhang et al., 2016; Li et al., 2017;).

\section{Conclusion}

To our knowledge, few studies investigated the influence of soil aggregates on microbial communities in sandy soil profile. Microbial interactions and key species significantly changed between top- and clay-layer soils due to the more intense competition in clay-layer soils, thereby inducing the niche differentiation through soil profile. Small-size aggregates typically in deeper clay-layer soils, relative to macroaggregates from the top-layers, play a more important role in determining the microbial community abundance and structure. The combined analysis of soil structure, microbial community composition and microbial networks provided a comprehensive insight in evaluating the influencing factors on variations of soil microbial community in sandy soil profile. Nevertheless, studies on nutrients and microbial community structure within different size aggregates are needed to better understand the mechanisms of niche differentiation in soil profile under long-term agricultural practice. 


\section{Conflict of interest}

The authors declare no conflict of interest.

\section{Acknowledgments}

The authors acknowledge the financial supports of the National Basic Research Program of China (Grant no. 2016YFD0200306), the National Natural Science Foundation of China (Grant no. 41877412), and the Scholarship of the 'National 1000 (Young) Talents Program' of China.

\section{Electronic supplementary material}

Supplementary material is available in the online version of this article at https://doi.org/10.1007/s42832-021-0095-1 and is accessible for authorized users.

\section{References}

Acosta-Martínez, V., Dowd, S.E., Bell, C.W., Lascano, R., Booker, J. D., Zobeck, T.M., Upchurch, D.R., 2010. Microbial community composition as affected by dryland cropping systems and tillage in a semiarid sandy soil. Diversity (Basel) 2, 910-931.

Allison, S.D., Wallenstein, M.D., Bradford, M.A., 2010. Soil carbon response to warming dependent on microbial physiology. Nature Geoscience 3, 336-340.

Bao, S.D., 2000. Soil and agricultural Chemistry analysis. 3 th ed Beijing: China Agriculture Press, 226

Barber, N.A., Chantos-Davidson, K.M., Amel Peralta, R., SherwoodJ P., SwingleyW.D., 2017. Soil microbial community composition in tallgrass prairie restorations converge with remnants across a 27 year chronosequence. Environmental Microbiology 19, 31183131.

Bending, G.D., Turner, M.K., Rayns, F., Marx, M.C., Wood, M., 2004. Microbial and biochemical soil quality indicators and their potential for differentiating areas under contrasting agricultural management regimes. Soil Biology \& Biochemistry 36, 1785-1792.

Blume, E., Bischoff, M., Reichert, J.M., Moorman, T., Konopka, A., Turco, R.F., 2002. Surface and subsurface microbial biomass, community structure and metabolic activity as a function of soil depth and season. Applied Soil Ecology 20, 171-181.

Bowen, J.L., Morrison, H.G., Hobbie, J.E., Sogin, M.L., 2012. Salt marsh sediment diversity: a test of the variability of the rare biosphere among environmental replicates. ISME Journal 6 , 2014-2023.

Brockett, B.F.T., Prescott, C.E., Grayston, S.J., 2012. Soil moisture is the major factor influencing microbial community structure and enzyme activities across seven biogeoclimatic zones in western Canada. Soil Biology \& Biochemistry 44, 9-20.

Caporaso, J.G., Kuczynski, J., Stombaugh, J., Bittinger, K., Bushman F.D., Costello, E.K., Fierer, N., Peña, A.G., Goodrich, J.K., Gordon, J.I., Huttley, G.A., Kelley, S.T., Knights, D., Koenig, J.E., Ley, R.E., Lozupone, C.A., McDonald, D., Muegge, B.D., Pirrung, M.,
Reeder, J., Sevinsky, J.R., Turnbaugh, P.J., Walters, W.A., Widmann, J., Yatsunenko, T., Zaneveld, J., Knight, R., 2010. QIIME allows analysis of high-throughput community sequencing data. Nature Methods 7, 335-336.

Castellazzi, M.S., Brookes, P.C., Jenkinson, D.S., 2004. Distribution of microbial biomass down soil profiles under regenerating woodland. Soil Biology \& Biochemistry 36, 1485-1489.

Cheng, X., Luo, Y., Xu, X., Sherry, R., Zhang, Q., 2011. Soil organic matter dynamics in a North America tallgrass prairie after $9 \mathrm{yr}$ of experimental warming. Biogeosciences 8, 1487-1498.

Cho, B.C., Jang, G.I., 2014. Active and diverse rainwater bacteria collected at an inland site in spring and summer 2011. Atmospheric Environment 94, 409-416.

Davinic, M., Fultz, L.M., Acosta-Martinez, V., Calderón, F.J., Cox, S. B., Dowd, S.E., Allen, V.G., ZakJ.C., Moore-KuceraJ., 2012. Pyrosequencing and mid-infrared spectroscopy reveal distinct aggregate stratification of soil bacterial communities and organic matter composition. Soil Biology \& Biochemistry 46, 63-72.

Deng, Y., He, Z., Xiong, J., Yu, H., Xu, M., Hobbie, S.E., Reich, P.B., Schadt, C.W., Kent, A., Pendall, E., Wallenstein, M., Zhou, J.Z., 2016. Elevated carbon dioxide accelerates the spatial turnover of soil microbial communities. Global Change Biology 22, 957-964.

Deng, Y., He, Z.L., Xu, M.Y., Qin, Y.J., Van Nostrand, J.D., Wu, L.Y., Roe, B.A., Wiley, G., Hobble, S.E., Relch, P.B., Zhou, J.Z., 2012b. Elevated carbon dioxide alters the structure of soil microbial communities. Applied and Environmental Microbiology 78, 29912995.

Deng, Y., Jiang, Y.H., Yang, Y.F., He, Z.L., Luo, F., Zhou, J.Z., 2012a. Molecular ecological network analyses. BMC Bioinformatics 13, 113-132.

Drenovsky, R.E., Vo, D., Graham, K.J., Scow, K.M., 2004. Soil water content and organic carbon availability are major determinants of soil microbial community composition. Microbial Ecology 48, 424430.

Ebrahimi, A., Or, D., 2016. Microbial community dynamics in soil aggregates shape biogeochemical gas fluxes from soil profiles upscaling an aggregate biophysical model. Global Change Biology 22, 3141-3156.

Edgar, R.C., 2010. Search and clustering orders of magnitude faster than BLAST. Bioinformatics (Oxford, England) 26, 2460-2461.

Eilers, K.G., Debenport, S., Anderson, S., Fierer, N., 2012. Digging deeper to find unique microbial communities: the strong effect of depth on the structure of bacterial and archaeal communities in soil. Soil Biology \& Biochemistry 50, 58-65.

Ekelund, F., Ronn, R., Christensen, S., 2001. Distribution with depth of protozoa, bacteria and fungi in soil profiles from three Danish forest sites. Soil Biology \& Biochemistry 33, 475-481.

Fierer, N., Schimel, J.P., Holden, P.A., 2003. Variations in microbial community composition through two soil depth profiles. Soil Biology \& Biochemistry 35, 167-176.

Fisher, C.K., Mehta, P., 2014. Identifying keystone species in the human gut microbiome from metagenomic timeseries using sparse linear regression. PLoS One 9, e102451.

Fritze, H., Pietikainen, J., Pennanen, T., 2000. Distribution of microbial biomass and phospholipid fatty acids in Podzol profiles under 
coniferous forest. European Journal of Soil Science 51, 565-573.

Jiang, Y.J., Liu, M.Q., Zhang, J.B., Chen, Y., Chen, X.Y., Chen, L.J., Li, H.X., Zhang, X.X., Sun, B., 2017. Nematode grazing promotes bacterial community dynamics in soil at the aggregate level. ISME Journal 11, 2705-2717.

Kandeler, E., Marschner, P., Tscherko, D., Gahoonia, T.S., Nielsen, N. E., 2002. Microbial community composition and functional diversity in the rhizosphere of maize. Plant and Soil 238, 301-312.

Kramer, S., Marhan, S., Haslwimmer, H., Ruess, L., Kandeler, E., 2013. Temporal variation in surface and subsoil abundance and function of the soil microbial community in an arable soil. Soil Biology \& Biochemistry 61, 76-85.

Langille, M.G.I., Zaneveld, J., Caporaso, J.G., McDonald, D., Knights, D., Reyes, J.A., Clemente, J.C., Burkepile, D.E., Thurber, R.L.V., Knight, R., Beiko, R.G., Huttenhower, C., 2013. Predictive functional profiling of microbial communities using 16S rRNA marker gene sequences. Nature Biotechnology 31, 814-821.

Li, Y.T., Adams, J., Shi, Y., Wang, H., He, J.S., Chu, H.Y., 2017. Distinct soil microbial communities in habitats of differing soil water balance on the Tibetan Plateau. Scientific Reports 7, 46407.

Long, T., Or, D., 2005. Aquatic habitats and diffusion constraints affecting microbial coexistence in unsaturated porous media. Water Resources Research 41, 2453-2454.

Louca, S., Parfrey, L.W., Doebeli, M., 2016. Decoupling function and taxonomy in the global ocean microbiome. Science 353,1272 1277.

Ma, B., Wang, H.Z., Dsouza, M., Lou, J., He, Y., Dai, Z.M., Brookes, P. C., Xu, J.M., Gilbert, J.A., 2016. Geographic patterns of cooccurrence network topological features for soil microbiota at continental scale in eastern China. ISME Journal 10, 1891-1901.

Mandiola, M., Studdert, G.A., Domínguez, G.F., Videla, C.C., 2011. Organic matter distribution in aggregate sizes of a mollisol under contrasting managements. Journal of Soil Science and Plant Nutrition 11, 47-57.

Marschner, P., Kandeler, E., Marschner, B., 2003. Structure and function of the soil microbial community in a long-term fertilizer experiment. Soil Biology \& Biochemistry 35, 453-461.

Martirosyan, V., Ehrlich, R., Frend, Y., Barness, G., Steinberger, Y., 2013. Spatial heterogeneity of a microbial community in a sandy soil ecosystem. Pedobiologia 56, 195-203.

Mummey, D.L., Rillig, M.C., Six, J., 2006. Endogeic earthworms differentially influence bacterial communities associated with different soil aggregate size fractions. Soil Biology \& Biochemistry 38, 1608-1614.

Nelson, D.W., Sommers, L.E., 1982. Total carbon, organic carbon, and organic matter. In: Page, A.L., Miller, R.H., Keenay, D.R., eds. Methods of Soil Analysis. 2nd ed. ASA and SSSA, Madison: WI., 539-580.

Nie, M., Pendall, E., Bell, C., Wallenstein, M.D., 2014. Soil aggregate size distribution mediates microbial climate change feedbacks. Soil Biology \& Biochemistry 68, 357-365.

Or, D., Smets, B.F., Wraith, J.M., Dechesne, A., Friedman, S.P., 2007. Physical constraints affecting bacterial habitats and activity in unsaturated porous media - a review. Advances in Water Resources 30, 1505-1527.
Petersen, C.T., Hansen, E., Larsen, H.H., Hansen, L.V., HauggaardNielsen, H., 2016. Pore-size distribution and compressibility of coarse sandy subsoil with added biochar: physical properties of sand with added biochar. European Journal of Soil Science 67, 726-736.

Qin, S.P., Hu, C.S., He, X.H., Dong, W.X., Cui, J.F., Wang, Y., 2010. Soil organic carbon, nutrients and relevant enzyme activities in particle-size fractions under conservational versus traditional agricultural management. Applied Soil Ecology 45, 152-159.

Sanesi, G., Certini, G., 2005. The umbric epipedon in the $N$ Apennines, Italy-an example from the Vallombrosa Forest. Journal of Soil Science and Plant Nutrition 168, 392-398.

Six, J., Bossuyt, H., Degryze, S., Denef, K., 2004. A history of research on the link between (micro)aggregates, soil biota, and soil organic matter dynamics. Soil \& Tillage Research 79, 7-31.

Six, J., Elliott, E.T., Paustian, K., 2000. Soil structure and soil organic matter: ii. a normalized stability index and the effect of mineralogy. Soil Science Society of America Journal 64, 1042-1049.

Smith, A.P., Marín-Spiotta, E., De Graaff, M.A., Balser, T.C., 2014. Microbial community structure varies across soil organic matter aggregate pools during tropical land cover change. Soil Biology \& Biochemistry 77, 292-303.

Smith, M.D., Knapp, A.K., 2003. Dominant species maintain ecosystem function with non-random species loss. Ecology Letters 6, 509-517.

Sradnick, A., Murugan, R., Oltmanns, M., Raupp, J., Joergensen, R. G., 2013. Changes in functional diversity of the soil microbial community in a heterogeneous sandy soil after long-term fertilization with cattle manure and mineral fertilizer. Applied Soil Ecology 63, 23-28.

Sung, J., Kim, S., Cabatbat, J.J.T., Jang, S., Jin, Y.S., Jung, G.Y., Chia, N., Kim, P.J., 2017. Global metabolic interaction network of the human gut microbiota for context-specific community-scale analysis. Nature Communications 8, 15393.

Trumbore, S., 2000. Age of soil organic matter and soil respiration: radiocarbon constraints on belowground $\mathrm{C}$ dynamics. Ecological Applications 10, 399-411.

Vos, M., Wolf, A.B., Jennings, S.J., Kowalchuk, G.A., 2013. Microscale determinants of bacterial diversity in soil. FEMS Microbiology Reviews 37, 936-954.

Walker, B., Kinzig, A., Langridge, J., 1999. Plant attribute diversity, resilience, and ecosystem function: The nature and significance of dominant and minor species. Ecosystems (New York, N.Y.) 2, 95113.

Wang, G., Or, D., 2013. Hydration dynamics promote bacterial coexistence on rough surfaces. ISME Journal 7, 395 404.

Wang, Q., Garrity, G.M., Tiedje, J.M., Cole, J.R., 2007. Naive bayesian classifier for rapid assignment of rRNA sequences into the new bacterial taxonomy. Applied and Environmental Microbiology 73, 5261-5267.

Wang, S., Wang, X.B., Han, X.G., Deng, Y., 2018. Higher precipitation strengthens the microbial interactions in semi-arid grassland soils. Global Ecology and Biogeography 27, 570-580.

Xu, T.L., Chen, X., Hou, Y.H., Zhu, B., 2021. Changes in microbial biomass, community composition and diversity, and functioning 
with soil depth in two alpine ecosystems on the Tibetan plateau. Plant and Soil 459, 137-153.

Ze, X., Mougen, F.L., Duncan, S.H., Louis, P., Flint, H.J., 2013. Some are more equal than others: the role of "keystone" species in the degradation of recalcitrant substrates. Gut Microbes 4, 236-240. Zhang, X.M., Johnston, E.R., Li, L.H., Konstantinidis, K.T., Han, X.G., 2016. Experimental warming reveals positive feedbacks to climate change in the Eurasian Steppe. ISME Journal 11, 885-895. 